\title{
EL NACIMIENTO DE LA NOVELA EN CUBA
}

\author{
POR \\ ANTON ARRUFAT \\ UNEAC
}

Entre las cuestiones que no han preocupado a los historiadores de la literatura cubana hay una que me interesa destacar. Ignoro cómo podría formularse con exactitud. Pero es algo que tiene relación con el surgimiento, en un momento determinado y no en otro, de nuestra novelística. Digo en un momento determinado porque, en los años que median entre 1830 y 1840 , la ficción narrativa como género empieza a interesar a nuestros escritores. Durante esa década comienza a ejercitarse la prosa de ficción y la imaginación busca estructurar un relato. Se medita en la ficción como cuestión en sí misma; el escritor emplea la prosa no como ensayista, historiador o filósofo, sino como narrador de ficciones. La novela se hace cuestión, preocupa como forma singular.

La prosa cubana hasta ese momento, obra de Félix Varela o de Arango y Parreño (o de Domingo del Monte en la crítica literaria), servía para la meditación, el informe, los memoriales a la corte española. Sólo en Heredia podemos encontrar una prosa que se acerque a la narración artística: la que emplea en sus cartas de viaje cuando visita las cataratas del Niágara o sube a la pirámide de Toluca. Ya su prosa posee cierto dinamismo descriptivo, una organización interior rodea el objeto identificándose con él, tratando de definirlo por asociaciones y metáforas. Es una prosa cálida y temperamental. Pero todavía no es prosa de ficción. No obstante, Heredia intentó la narración imaginativa. Compuso algunos cuentos, Abuzaid, Historia de un salteador italiano, y en ellos su prosa retrocede. Adquiere un aire didáctico y moralista, pierde la ductilidad fluyente de sus cartas de viaje y parece más apropiada para el apólogo dieciochesco que para el cuento, tal como se concebía ya en su época.

La prosa narrativa cubana empieza en 1837 con relatos cortos y prosigue 
su desarrollo con las dos primeras novelas escritas en Cuba, ambas de 1839, El guajiro, de Cirilo Villaverde, y Francisco, de Suárez y Romero. Estas son, en rigor, las primeras novelas que escribe un cubano. El año anterior se habían publicado dos relatos importantes: Una pascua en San Marcos, de Ramón de Palma, y Antonelli, de José Antonio Echeverría. Con cierto descuido, propio de nuestra historiografía literaria, se sitúan estas dos narraciones dentro de la novela. En realidad, se trata de cuentos largos o de lo que los franceses llaman nouvelles. Ninguna de las dos rebasa las cuarenta cuartillas y carecen de la complejidad de relaciones de la auténtica novela. Cuentan un solo hecho, y brevemente. Dan al relato un giro inesperado. Refiriéndose a este tipo de narraciones, Heyse desarrolló la teoría de «la silueta y el halcón»: una línea esquemática y un clímax.

$\mathrm{Y}$ ahora podemos preguntarnos por qué la novela se escribe en tal fecha precisamente y no en otra anterior o posterior. Por qué en la década del treinta. Me parece que el hecho debe tener sentido, un significado. Se ha dicho, y con sobrada razón, que la novela es género tardío. Villaverde, Suárez y Romero son posteriores al poeta Heredia. En 1825 edita Heredia sus poesías en la ciudad de Nueva York, durante su exilio político. Aunque él es la figura máxima de la poesía cubana de su momento, tampoco está solo. Otros poetas lo han precedido y otros son sus contemporáneos. Existe un movimiento de poesía a su alrededor, del cual puede sentirse participante, heredero. Escribir poesía constituye una actividad habitual. Buena o mala, se escribe y se publica en revistas y periódicos. Si no hay muchos libros de poesía impresos se debe a la carencia de editores y a la falta de mercado. Pero los poemas están ahí, no tiene el poeta más que reunirlos llegado el momento de la publicación. Había, por tanto, poetas líricos, pero no había novelistas. Existía la poesía con cierta resonancia social, pero no había novelas. Ninguna ficción auténtica hasta Ramón de Palma, hasta Villaverde, reales iniciadores, en calidad y precedencia histórica. Sus primeras obras son, como observa Manuel de la Cruz, un documento precioso para conocer la génesis y desarrollo del género en nuestra literatura. Palma, con su cuento Una pascua en San Marcos -que todavía no ocupa en los manuales ni en la valoración crítica el lugar que merece como precursor-, Villaverde, Suárez y Romero, consagraron sus energías a darle independencia, tono y carácter genuino a la narración entre nosotros.

Ahora bien: el esfuerzo creador personal no es suficiente para explicar el nacimiento de una novelística. ¿Por qué se interesaron en hacerlo? ¿Y por qué en la década del treinta? Algunos han tratado de responder - indirectamente- a esta cuestión insistiendo en resaltar la prédica de Domingo 
del Monte, su influencia y orientaciones, su afán en despertar el interés de sus contemporáneos y amigos por la ficción narrativa. Esto es cierto, como es cierto el efecto, aunque incompleto. La prédica de Del Monte es más bien una consecuencia, no la causa. Del Monte, de las inteligencias más perspicaces de su época, verdadero representante de su clase social, animador en su propia casa de una tertulia de largo influjo en la literatura cubana, se preocupó sin duda por la novela. Llegó a escribir, él que poco escribía, un extenso ensayo dedicado al tema. Pero es evidente que su propósito en él era esencialmente informativo. Publicado en las páginas de la Revista Bimestre, en 1832, coincide con el «Ensayo sobre la novela» de Heredia, publicado en México en la misma fecha. Faltaban cinco años para que apareciera la primera ficción narrativa en la Isla. Ambos ensayos - - l de Heredia, de calidad excepcional- se sitúan fuera de la creación novelesca. Sus autores no escriben como novelistas que se refieren al género que practican. Hablan desde fuera. Para ellos, la creación novelesca en sí misma no constituye un problema. Basta leer el ensayo de Henry James El arte de la novela, por ejemplo, para comprobar la distancia. James está dentro de la novela, del «misterio de contar una historia»; su ensayo es una meditación acerca de cómo debiera escribirse y, sobre todo, acerca de la posición que una novela tiene en la sociedad. Ni en las de Del Monte ni en las de Heredia podemos encontrar este punto de vista, esta manera de situarse. En el Ensayo sobre la novela, además, al enjuiciar Heredia los errores de las novelas de Walter Scott, no comprende la importancia fundamental de este autor, apartándose así de la corriente creadora de la novela de su tiempo. No puede olvidarse que Scott, como Cooper y Manzoni - guías espirituales de Villaverde- colaboraron en fundar la novela realista, como reconoció Balzac en un pasaje célebre. Heredia renuncia a situarse dentro de esta corriente. Permanece al margen. Su juicio es exterior. El no está dentro de la creación novelística, como estarían luego Palma y Villaverde. Para ellos, Walter Scott resultaba esencial. Así nos lo hicieron saber en diversos artículos.

En el año clave de 1838, Ramón de Palma inserta en la revista $E l$ Album una crítica a las primeras narraciones de Villaverde, impresas en el año anterior. No sólo se trata de una crítica, un tanto amarga, a los relatos de su contemporáneo, sino de algo más. Es un pequeño estudio de la novela. En él, entre lugares comunes y torpezas, hallamos sorprendentes intuiciones. $\mathrm{Y}$ al contrario de lo que ocurre a Del Monte y a Heredia, Palma se sitúa ya dentro del género, habla como un novelista, como un autor de ficciones. Es ostensible el cambio de posición y perspectiva: Palma es un narrador que redacta un juicio crítico sobre otro narrador. Son los dos primeros cubanos en ocuparse del misterio de contar una 
historia. «Desde el descubrimiento de Cuba hasta la fecha - dice Palma de Villaverde, con el orgullo manifiesto de quien se refiere a un colega-, ningún otro ha publicado una colección de novelas originales».

En estas páginas memorables para la historia de la literatura cubana, se transparenta la idea tan elevada que Palma se ha forjado de su oficio. Abre su ensayo con un amplio gesto: la novela no es un pasatiempo, una diversión vana, sino una forma de conocimiento de la realidad. $\mathrm{Ni}$ en Heredia ni en Del Monte - tampoco en Milanés, quien redacta por esa fecha un artículo consagrado a la novela histórica - encontramos afirmación parecida. Palma reconoce que su siglo «es eminentemente positivo», que para algunos «la imaginación ha caducado», y el hombre busca ya en cada cosa alguna utilidad. Pero es en ello precisamente, en tal inclinación positiva, donde Palma, dando un giro imprevisto a la valoración habitual de la novela en su época, se dispone a fundamentar la importancia del género. «Verdad que a nuestro parecer no se ha sabido explicar claramente.» Una obra de imaginación, tal como Palma la concibe, no es inútil. Por el contrario, es una representación de la vida. «Ha llegado a ser la muestra de las creencias, las costumbres, las pasiones, los extravíos y el adelanto de los pueblos.» La novela, en realidad y rigor, es un medio de instrucción, «un reflejo de la sociedad a que pertenece». Palma ha tomado su arte realmente en serio. Llega a escribir esta sentencia orgullosa: «Un autor de novelas en el día es tan positivo como el más sólido matemático».

El ha sabido señalar el prejuicio contra la obra de ficción, la poca estima que los sabios tenían por este género de escritos. Lo ha dicho con ironía: «Entregados a estudios serios, no presumían que la sociedad pudiese recibir otro provecho sino el que resultase de las lucubraciones académicas.» Un gran novelista al que ya he mencionado, Henry James, recordó en pleno año 1884, y en la ilustrada Inglaterra, idéntica valoración. Si la superstición de que la novela era un pecado ya había desaparecido, subsistía una «cierta mirada oblicua» dirigida hacia cualquier narración que no se presentase como mentira, artificio o broma. La novela debía renunciar a su pretensión de tratar verdaderamente de la vida. Palma, en 1838 y desde el principio del ensayo, reivindica para la novela su posición en la sociedad. La convierte en muestra, es decir, en espejo. Y establece una relación dialéctica insospechada en un cubano de su tiempo: la novela refleja la realidad, la sociedad a que pertenece y, a la vez, influye en la realidad reflejada. Reflexiona con certeza: «si la novela fue efecto de otras causas, ella ha sido causa de otros efectos».

Dos años después, el 15 de septiembre de 1840, Sainte-Beuve publica en París su estudio sobre las novelas de Eugenio Sué. En uno de sus 
párrafos afirma que la literatura es expresión de la sociedad y que, al mismo tiempo, como observara Ramón de Palma, con todas las limitaciones de la situación colonial en que vivía, la sociedad es expresión y traducción de la literatura. Una obra toca un punto sensible, y ese punto, una vez excitado, se desarrolla rápidamente y tiende a parecerse más a sí mismo. Lord Byron tuvo muy pronto una influencia sobre los hombres. « ¿Cuántas nobles imaginaciones - exclama Sainte-Beuve-alcanzadas por uno de sus rasgos, se han modelado a su semejanza!».

Para Palma, esta virtud de la novela $\longrightarrow$ o de la literatura en generaladquiere una gran importancia en la sociedad. Se convierte en bien público. Todo su ensayo descansa en la convicción de esta utilidad: hacer a muchos personas, a amplios sectores sociales, conscientes de sus inclinaciones latentes, de sus sentimientos, tornándoles más difícil ignorarlos o el mantenerse indiferentes. Palma propone, en el fondo, a la novela cubana de su momento, a un género que empezaba con él, con Villaverde, con Suárez y Romero, crear una atmósfera moral en la sociedad que impidiera prosperar a la injusticia.

En la importancia de estas páginas nuestra crítica no ha reparado. Son, en rigor, un verdadero manifiesto. En ellas se propone y anuncia la creación de la novela nacional, de la novela local, según se decía en el lenguaje de la época. De acuerdo con los supuestos de su ensayo-manifiesto, la novela cubana debe tender a la observación de la realidad, a la propiedad en los caracteres, a la naturalidad en el diálogo. Escoger asuntos cubanos, imitar la verdad, descubrir en el corazón humano los ocultos resortes. Pintar las acciones del hombre sin aislarlo de la naturaleza y de la sociedad en que se produce. Para él, ha dejado de ser un género estrecho, novela sentimental o de costumbres solamente. Las ve hermanadas: «en el día apenas se pinta una pasión que no esté enlazada con la historia y los usos de la época a que se refiere». Es el género literario que mayor cantidad de elementos ajenos puede contener, con tal que todo ello quede novelado, disuelto en la atmósfera de la ficción. Ramón de Palma apunta este hecho, que en nuestro tiempo no ha dejado de multiplicarse, del modo siguiente:

Desde la aparición de Cervantes ha extendido la novela su jurisdicción a todas las clases de la sociedad y a todos los ramos del saber humano. Sus páginas se han convertido en un animado panorama donde figuran personajes históricos o fingidos, se ventilan las más importantes cuestiones sociales y se dan lecciones severas de moral y de experiencia. Eminentemente dramática, tiene sobre el drama la ventaja de extender más su acción y de trazar con mayor acabamiento los caracteres: siempre verdadera en los incidentes 
y natural en los medios, puede elevarse hasta la altura de la epopeya, descender hasta el lenguaje del vulgo, inspirarse con el estro de la poesía lírica y adornarse con las sencillas flores del idilio.

Con sencillez, a veces con ingenuidad, Ramón de Palma traza, en pleno romanticismo latinoamericano, los principios de la novela realista.

Aquí encuentro una paradoja o conflicto que debo aclarar. Ramón de Palma, al igual que Villaverde y Suárez y Romero, eran románticos y estaban fuertemente influidos por el romanticismo francés. Sin embargo, no se hallaban cómodos dentro de sus límites. Se juzgaban a sí mismos, reprochándose haber «empapado el espíritu de una literatura enteramente extraña» a la naciente sociedad en que vivían. Encuentro en este conflicto una manifestación de la intensidad del momento histórico en que surge la novela cubana. Estos tres narradores, como otros que podrían citarse -Echeverría, Tanco-, son escritores conscientes de su diferencia. Están tratando de artizar una realidad no verbalizada, que todavía no ha sido escrita. Realidad que ellos llaman «virgen». Viven en un país sin entidad política. Manejan un instrumental ajeno, que ellos no han creado ni ha surgido de su propia realidad social, generado originalmente por una sociedad diversa de la suya, sociedad más estratificada y compleja. Habitando en un país sin historia escrita o conscientemente vivida, sin monumentos ni tradición actuante, el mismo Palma confiesa con tristeza, refiriéndose al romanticismo francés: «bien conocemos lo difícil que es libertarse del influjo de una nación cuyas letras nos seducen y cuyo poder y adelanto nos deslumbran».

Por esto, siendo románticos, introducen una rectificación dentro del romanticismo, si puedo expresarme así. Ellos viven la primera etapa nacionalista de nuestra historia, etapa que coincidió con el movimiento romántico en la cultura europea y americana. El romanticismo produjo en ellos un fenómeno singular y creó un problema diferente. Mientras el ideal romántico fomentaba una concepción idealista e imaginaria de la vida, los cubanos hacían frente al duro y realista deber de luchar por la entidad de la nación. Por todas partes sentían el apremio de un realismo moral y económico. El individualismo desatado y la interpretación del destino humano llena de patetismo y soledad el gusto por lo raro y los placeres de la melancolía, reñían hasta cierto punto con el afán de adelantamiento social y la lucha por crear una nación, abolir la trata de esclavos y finalmente la esclavitud misma. El artista literario se encontraba escindido entre el gusto romántico y la responsabilidad práctica, entre la iniciativa individual y las necesidades comunes. La herencia romántica se encontraba en conflicto con el realismo 
social y político. Este conflicto dotó al período y, en parte, a todo el siglo de singulares matices.

Hablo del romanticismo tal como lo concebían estos propios escritores. En un artículo, penetrante e irónico, Ramón de Palma lo define como deseo $\sin$ objeto, inquietud sin razón, un fastidio sin motivo. La necesidad de ser otra cosa distinta de lo que se es, gozar una felicidad ignorada, de oír un lenguaje desconocido... Hoy sabemos, como lo demuestran ciertos libros, entre ellos el de Roger Picard, que el romanticismo, matizado de diversas tendencias, tuvo una preocupación y un pensamiento sociales.

La novela como búsqueda constante de la realidad, producto inconfundible de un momento y un país, género independiente y valioso en su exploración del mundo social, es lo que Palma propone en su ensayo. De tal propósito participaron Villaverde y Suárez y Romero. Novela de textura social, típica del siglo. Quizá estos autores no escribieron una obra de resonancia internacional, pero estuvieron acordes, en sintonía, con las grandes aspiraciones de su tiempo. Y como buenos nacionalistas, las adaptaron al medio en que vivían. Esta «adaptación» produjo nuevas aspiraciones.

¿Cómo era realmente ese medio? Situados en la década del treinta, en los años en que nace la novela cubana, ¿tal medio podía nutrir una novelística que aspiraba, orgullosa de su función, a ser un «animado panorama» de todas las clases de la sociedad y todos los ramos del saber humano, a ser una representación luminosa de la vida?

Sin duda, la novela surge en un momento determinado, y no en otro, porque en ese momento la vida había alcanzado cierta intensidad. Desde el siglo XVIII, la vida cubana se había ido haciendo más densa progresivamente. Tan densa como para permitir el nacimiento de una novelística. En esta densidad me parece encontrar la causa de que se comience a escribir con las características propias de la novela social de la época. Los novelistas tenían algo que contar, la realidad comenzó a presentar aspectos novelescos. La vida se hizo más compleja, más apremiante. Si no alcanzó la complejidad de la sociedad francesa, la cual generó la posibilidad de que Balzac escribiera su gran obra narrativa - obra que nuestros primeros novelistas leían con atención y provecho-, alcanzó una complejidad superior a la etapa dieciochesca, en la que no se produjo ninguna novela. Las presiones competitivas se volvieron mayores, despertando pasiones y conflictos de cierta hondura, dentro de modalidades sociales más complicadas. Aunque las costumbres eran inestimables, según el mismo Villaverde observara, y tal inestabilidad acrecía las dificultades para escribir una novela, existían costumbres que pintar. Hacia ellas se volvieron estos hombres con afán. Estaban - fundamentalmente- interesados en descri- 
bir, en retratar o pintar como ellos decían, más que en narrar una historia. Con frecuencia ésta fue sólo un pretexto para entregarse a la descripción del mundo exterior.

La novela, género eminentemente urbano, ligado al desarrollo capitalista de la sociedad, apareció en La Habana y en Matanzas, ciudades marítimas. Por sus muelles se realizaban las actividades comerciales. El desarrollo de estas ciudades se hallaba sujeto a la actividad de sus puertos. Cuba era ya de los mayores abastecedores de azúcar del mundo. Por esos puertos salían miles de cajas de azúcar. Poco a poco la factoría se había transformado en colonia de plantaciones: la ganadería de la primera época cedió el paso a los tabacos y luego a los cafetales e ingenios azucareros. En los ingenios se introdujo la máquina de vapor, iniciándose la revolución industrial en la agricultura. A la generación de novelistas precedió una generación que se propuso incorporar la Isla al capitalismo industrial contemporáneo.

La Habana y Matanzas —en el resto de las ciudades no habrá novelas hasta muchos años después: pasada la década del cuarenta en Camagüey, a finales de siglo en Santiago-, ciudades enclavadas en provincias de gran desarrollo agrícola, con el mayor número de ingenios azucareros del país, estaban entre las más pobladas de la Isla. Según el censo de 1827, La Habana tenía más de cien mil habitantes. La corriente inmigratoria que contribuye a este aumento de población procedía, por una parte, de las colonias que España iba perdiendo: Florida, Louisiana, Haití, Colombia, México, y por otra, la más numerosa, de la trata de esclavos.

Eran ciudades cercanas a las zonas cafetaleras y a las zonas azucareras, las más grandes del país en ese momento. Las dos primeras novelas se desarrollan en estas zonas. El guajiro en la cafetalera, zona en la que el autor pasó su infancia, y Francisco —escrita en un ingenio de la provincia habanera-, en medio de las grandes dotaciones de esclavos. Son obras que parten de experiencias personales muy directas, casi documentos autobiográficos. Si Villaverde no dio con el gran tema de la sociedad en que vivía - no lo conseguirá hasta que escriba Cecilia Valdés-, Suárez y Romero, en su primera y única narración larga, logró plantear al menos el gran conflicto de su tiempo: la relación amo-esclavo. En 1841, dos años después de la redacción de Francisco, la Avellaneda expresará el mismo conflicto esencial en $S a b$.

Finalmente, la actividad editorial es bastante intensa en ambas ciudades. Se imprimen periódicos y revistas. Hay un interesante intercambio entre las dos ciudades: novelas que se escriben en La Habana se publican en Matanzas y viceversa. Ramón de Palma editará dos revistas importantes en años sucesivos: El Album y El Plantel, en las que se publicarán relatos 
y novelas cortas. El Faro Industrial imprimirá novelas en forma de folletines. Existen editores interesados en la ficción. Oliva publicará dos obras de Villaverde. Un hecho que es necesario destacar: Villaverde, el que más se ejercitó en la creación novelesca, llegó a ganar dinero con sus obras. Esto implica una demanda del público lector, demanda que no debe soslayarse si se quiere entender el surgimiento de la novela en estos años.

Con el desarrollo de la industria azucarera creció una rica clase de propietarios criollos. Clase emprendedora, esclavista y fastuosa, inclinada a los conocimientos prácticos y los goces sensuales. Así aparecen retratados en nuestras primeras novelas don Cándido Gamboa o la señora Mendizábal. Aficionados a los naipes y a la comida, al vestir y al paseo en coche. Los hombres, de grandes pasiones eróticas; las mujeres, profundamente inhibidas. Se hicieron construir, por sus arquitectos y sus esclavos, mansiones y palacios. Las ciudades empezaron a cubrirse de construcciones civiles; los campos, de quintas y casas de recreo, cercanas a sus plantaciones y cafetales, pero distantes de los feos barracones de madera donde habitaban los esclavos, tatuados y semidesnudos, de las calderas humeantes y el punzante olor dulzón del bagazo. En sus costumbres, trataron de adquirir cierta elegancia. Fiestas y saraos, bailes al compás de la contradanza y el minué. Industriales y mercaderes enriquecidos, o negreros consumados como don Cándido de Gamboa, compraron títulos de nobleza. Labraron en las fachadas monumentales de sus palacios sus escudos heráldicos. Vestidos con telas finas de Francia, que cortaban sus modistos y sastres, calzaban zapatos de raso o pieles delicadamente curtidas, que les hacían sus zapateros particulares. Se cuidaban el cuerpo: médicos los atendían en sus propias habitaciones, acudían a casas de salud y descanso, construidas en torno a los baños de aguas minerales, y hacían ejercicio físico para ejercitar los músculos ociosos: esclavos domésticos realizaban las rudas tareas, los vestían y calzaban. Viajaban en lujosos quitrines por los recientes paseos públicos, hasta ese momento casi inexistentes, o se detenían a la puerta de las tiendas y sin bajarse realizaban sus compras: los dependientes acudían con las piezas de tela en los brazos hasta el mismo carruaje. Seguían el paseo por la calle Muralla, por Obispo y O'Reilly. Ante sus ojos de gente bien, inquisitivos y seguros, desfilaban muebles de estilo inglés, la joyería francesa, las porcelanas y la platería, espejos venecianos que reflejaban la luz de los atardeceres tropicales.

El desarrollo económico del país produjo a su vez una capa de hombres pobres, agudizando la separación entre las clases. A las mansiones, las casas humildes, de materiales deleznables, pasto de incendios y huracanes. A la mesa de caoba pulida y los candelabros de plata, la mesa de pino y la vela de sebo. A la cama con ricas colgaduras, la cama de simple bastidor 
y una tela. A los sillones de rejilla, los de paja o cuero. Ni alfombras ni cortinas ni dorados. La mesa humilde: tasajo, viandas hervidas. Al sombrero de fina y fresca paja de Italia, adornado de cintas y flores, al túnico de olán o muselina, un pañuelo de Madrás anudado al pelo, collares de abalorios, faldas de percal. A la levita de paño y la caña de Indias con puño de oro, a los zapatos de charol y el pañuelo de batista en la mano, empapado en agua de Colonia, los pantalones listados de lino, la camisa de cuadros azules, el sombrerón de yarey, los zapatos de baqueta, y en la mano el veguero barato. Imágenes de santos pintarrajeadas y la palma bendita colgada de la pared. En los cementerios, una parte de tumbas de mármol, con ángeles y trompetas, otra parte de tierra sola, la fosa común.

Al conocido conflicto de clases, la sociedad cubana agrega otro: la segregación racial. A la división en clases, la escisión en estratos étnicos. Sociedad rígida y doblemente jerarquizada. Los antagonismos de clase se hallaban agudizados por esta división racial. Tal organización dotaba a la sociedad cubana de complejidad, de textura social. Significaba la presencia suficiente para exponer en una novela una variedad de modales, de conductas entrelazadas, oportunidad para que el novelista cumpliera su tarea.

Habíamos visto que la poesía lírica aparece antes que la novela. (Hubo en Cuba una pequeña épica en el siglo XVII con El espejo de paciencia, si no es una superchería literaria del grupo delmontino). El arte del novelista tiende a preocuparse por los otros, por la cuestión de las relaciones entre los hombres. Se deja arrastrar por los destinos ajenos. De esto no se preocupa la lírica. La lírica es monodológica, diría el filósofo Leibniz. Para quien intenta trazar la crónica de una época -como se propusieron nuestros primeros novelistas- saber oír, saber mirar a los otros, acercarse a las cosas y al color de las cosas, es lo más importante. El arte de escribir novelas implica dominar el arte de oír y de ver. Arte sutil y difícil: exige finura, don de observación, desprendimiento del propio yo. Exige modestia: la aceptación de la existencia ajena. Sin ellos, sin la complicación creciente de una sociedad, sin la intensidad de la vida en derredor del autor de ficciones, ésta no es posible. Heredia podía escribir sobre sí mismo, Villaverde necesitaba de los demás tanto como de sí mismo. Necesitaba costumbres, bailes, excursiones campestres, instituciones, jerarquías sociales, palacios y casas de techo de guano, una tabaquera de carey con filetes dorados, quien se jugara mil onzas de oro a un naipe o a las patas de un gallo, lo menudo y prosaico, lo lujoso y espiritual, un arte de la cocina, modos de vestir y de hablar, necesitaba antagonismos, dinámica social, conflictos. El poeta oye una voz interior, la suya; el novelista oye muchas voces, entre las que oye también la suya. Si el novelista tiene necesidad de objetivarse - no olvidemos que una novela es en gran parte autobiogra- 
fía transformada-, para lograrlo requiere de las vidas ajenas, y es con ellas, mediante ellas y contra ellas como podrá conseguirlo. Sin que la vida cubana alcanzara contextura, problemas, no hubiera sido posible una novelística. Los años de la década del treinta inauguran la novela entre nosotros, porque inauguran en nuestra historia una mayor complejidad e intensidad de vida. 
